\title{
Emerging clinical applications of selected biomarkers in melanoma
}

This article was published in the following Dove Press journal:

Clinical, Cosmetic and Investigational Dermatology

30 January 2015

Number of times this article has been viewed

\author{
Michael T Tetzlaff' \\ Carlos A Torres-Cabala ${ }^{1,2}$ \\ Penvadee \\ Pattanaprichakul ${ }^{1,3}$ \\ Ronald P Rapini ${ }^{2}$ \\ Victor G Prieto ${ }^{1,2}$ \\ Jonathan L Curry ${ }^{1,2}$
}

'Department of Pathology, Section of Dermatopathology, ${ }^{2}$ Department of Dermatology, The University of Texas MD Anderson Cancer Center, Houston, TX, USA; ${ }^{3}$ Department of Dermatology, Faculty of Medicine, Siriraj Hospital, Mahidol University, Bangkok, Thailand
Correspondence: Jonathan L Curry Department of Pathology, Unit 85, The University of Texas MD Anderson Cancer Center, 1515 Holcombe Blvd, Houston, TX 77030, USA

$\mathrm{Tel}+\mathrm{I} 7 \mid 37922956$

Fax + I 7137458228

Email jlcurry@mdanderson.org
Abstract: Melanoma is a lethal skin disease with a mostly predictable clinical course according to a known constellation of clinical and pathologic features. The distinction of melanoma from benign melanocytic nevus is typically unequivocol; however, there is a subset of tumors known for its diagnostic challenges, development of late metastases, and difficulties in treatment. Several melanocytic tissue biomarkers are available that can facilitate the histopathologic interpretation of melanoma as well as provide insight into the biologic potential and mutational status of this disease. This review describes the clinical application of some of these established and emerging tissue biomarkers available to assess melanocytic differentiation, vascular invasion, mitotic capacity, and mutation status. The selected tissue biomarkers in this review include MiTF, Sox10, D2-40, PHH3, H3KT (anti-H3K79me3T80ph), anti-BRAFV600E, and anti-BAP-1.

Keywords: immunohistochemistry, melanocytic differentiation, histone marks, BRAFV600E

\section{Introduction}

Melanoma is a deadly skin disease known for its aggressive clinical behavior and high propensity for lethal metastasis. ${ }^{1,2}$ High throughput genomic analysis with nextgeneration sequencing technology has allowed us to interrogate whole exomes and genomes in melanoma, which have provided insight to the key oncogenic pathways involved in melanomagenesis ${ }^{3,4}$ RAS/mitogen-activated protein kinase (MAPK) pathway and PI3 kinase/AKT pathways continue to emerge as key driver mutations in melanomas. ${ }^{5,6}$ The most frequent oncogenic driver mutation identified in melanoma is in $B R A F$, which exists in approximately $50 \%-60 \%$ of patients with this malignancy. ${ }^{7,8}$ Molecular techniques available for evaluation of BRAFV600E mutations in melanoma are further reviewed in detail elsewhere. ${ }^{9,10}$

Regulation of melanogenesis in melanocytes involves a series of complex biochemical steps, with conversion of L-tyrosine to L-3,4 dihydroxyphenylalanine (L-DOPA) by tyrosinase to final melanin product. ${ }^{11}$ In fact, it is now clear that L-tyrosine and L-DOPA can act as positive regulators of melanogenesis and melanocyte function. ${ }^{12}$ Tyrosinase is central to melanogenesis, and transcriptional regulation of tyrosinase involves several MiTF-binding sites, further reviewed by Slominski et al. ${ }^{11}$ Melanogenic activity is dependent on binding of MiTF to melanogenesis-related proteins; thus, the development of melanocytes in the epidermis and in the follicle is conserved as well as melanin production in melanocytes and melanoma cells..$^{12,13}$

Corticotropin releasing hormone and proopiomelanocortin are known to be produced in the skin in response to environmental stress. ${ }^{14}$ Melanocytes and melanoma cells predominantly express the $\alpha$ isoform of corticotropin releasing hormone 
receptor-1 (CRHR-1). Upon CRHR-1 $\alpha$ activation, cyclic adenosine monophosphate is produced, and through release of proopiomelanocortin peptides (ACTH, $\alpha-\mathrm{MSH}$, $\beta$-endorphin), stimulates melanin production in melanocytes. ${ }^{15}$ Activation of CRHR-1 inhibits melanocytes and melanoma cell proliferation, making selective antagonists a rational target for future melanoma targeted therapy. ${ }^{15}$

The treatment for localized primary melanoma is surgical excision with adequate margins, and for a subset of patients with high-risk tumors, lymphatic mapping and sentinel lymph node biopsy is recommended. Adjuvant interferon alfa therapy and chemotherapy have been the standard treatment for patients with advanced stage disease. However, more recently, targeted therapy with small molecule inhibitors (eg, vemurafenib) has revolutionized melanoma treatment. In a Phase III trial (BRIM-3), patients who harbor BRAFV600E mutant melanomas who were treated with vemurafenib had better clinical response and overall survival rates than did patients treated with chemotherapy. ${ }^{16}$ Selective targeted therapy against other intracellular molecules (eg, NRAS, MEK, KIT) are under clinical trials and hold promise for future melanoma therapy. Several publications review current melanoma-targeted therapy. ${ }^{17-19}$

Clinical response to vemurafenib therapy may be dramatic, with complete shrinkage of tumor burden in patients; however, the duration of response has been limited and eventual disease progression frequently occurs within months of therapy. ${ }^{16}$ Resistant mechanisms have curtailed long-term therapeutic benefit from vermurafenib therapy; thus, targeting multiple pathways or combined therapy with immune check point blockade (eg, anti-CTLA4 and anti-PD-L1) are under clinical investigation. ${ }^{20-23}$ Further review of resistant mechanisms via protective effects of insulin on melanoma cells or by activation of the PI3K/AKT pathway can be examined in a study by Chi et al. ${ }^{24}$ Future application of nanotechnology in melanoma to improve therapeutic efficacy is further reviewed by Chen et al. ${ }^{25}$

Accurate diagnosis of melanoma remains critical to further clinical management. Melanoma can demonstrate a wide range of morphologic features and may be misinterpreted as other human malignancies (eg, sarcomas, squamous cell carcinomas, Paget's disease, and lymphomas). Thus, melanoma is known as the "great mimicker." ${ }^{26}$ Diagnosis of melanoma can be further complicated since a subset of ambiguous melanocytic lesions may demonstrate features overlapping with melanoma and benign nevi (in particular, Spitz nevi). ${ }^{27}$ These characteristics make the histologic diagnosis of melanoma challenging for even the most experienced dermatopathologists.
To help distinguish melanoma from its imitators, a variety of tissue biomarkers and ancillary techniques (eg, immunohistochemical [IHC] analysis or fluorescence in situ hybridization) are currently available. In fact, hundreds of tissue biomarkers are available in clinical laboratories for diagnosing melanoma and determining the prognosis and mutation status of this devastating skin disease. This review provides an update on the clinical applications of some of the established and emerging melanoma tissue biomarkers used at The University of Texas MD Anderson Cancer Center. Specifically, we will review the following melanoma tissue biomarkers (Table 1) :1) melanocytic differentiation [MiTF and Sox10]; 2) vascular invasion [D2-40 and dual IHC marker with MiTF/D2-40 and Sox10/D2-40]; 3) mitotic figures [PHH3, dual IHC marker with Mart-1/PHH3 and H3KT (anti-H3K79me 3T80ph)]; and 4) mutation status [anti-BRAFV600E, anti-BAP-1].

\section{Markers of melanocytic differentiation MiTF}

MiTF (microphthalmia-associated transcription factor) functions in the development and differentiation of a variety of cell types, including melanocytes. ${ }^{28}$ There are ten isoforms of MiTF, with the M isoform specifically expressed in melanocytes. ${ }^{29}$ MiTF regulates the transcription of genes (eg, tyrosinase, tyrosinase-related protein 1 and 2) involved in melanin synthesis and survival of postnatal melanocytes. ${ }^{28,30,31}$ Thus, MiTF is critical for pigment synthesis and melanocyte differentiation. MiTF protein functions in the nucleus of melanocytes and can be recognized with antibodies directed against it. The D5 antibody recognizes human MiTF. ${ }^{32}$

The sensitivity of MiTF in melanocytic lesions exceeds $80 \%$ and is similar to that of HMB45. ${ }^{33}$ In desmoplastic melanomas, however, the sensitivity of MiTF dramatically decreases to less than $55 \%$ according to some studies. ${ }^{32,34}$ The low sensitivity of MiTF in desmoplastic melanoma is comparable to that of HMB45, a marker of premelanosomal glycoprotein 100. Therefore, MiTF appears to exhibit sensitivity comparable to that of HMB45 in melanocytic neoplasms. MiTF and HMB45 differ, however, in their specificity. HMB45 is a highly specific marker with greater than $97 \%$ specificity for melanocytic differentiation. ${ }^{35,36}$ In contrast, the specificity of MiTF in melanocytic lesions is less, and the widespread use of this biomarker alone in evaluating melanocytic lesions is an important pitfall. MiTF has been shown to highlight cells other than melanocytes and nonmelanocytic neoplasms. In particular, MiTF reactivity 
Table I List of selected tissue biomarkers in melanoma

\begin{tabular}{|c|c|c|c|c|c|c|}
\hline Marker & Property & Clone (vender) & Concentration & $\begin{array}{l}\text { IHC } \\
\text { pattern }\end{array}$ & Internal control & Clinical application \\
\hline MiTF & $\begin{array}{l}\text { Nuclear transcription } \\
\text { factor }\end{array}$ & $\begin{array}{l}\text { D5 } \\
\text { (Thermo Scientific) }\end{array}$ & $\mathrm{I}: 40$ & $\mathrm{~N}$ & $\begin{array}{l}\text { Epidermal } \\
\text { melanocytes, } \\
\text { adnexae }\end{array}$ & $\begin{array}{l}\text { Distinction from } \\
\text { melanocytic hyperplasia } \\
\text { and LM confirmation } \\
\text { of melanocytic } \\
\text { differentiation }\end{array}$ \\
\hline Sox 10 & $\begin{array}{l}\text { Nuclear transcription } \\
\text { factor }\end{array}$ & $\begin{array}{l}\text { Polyclonal } \\
\text { (Cell Marque) }\end{array}$ & $\mathrm{I}: 50$ & $\mathrm{~N}$ & $\begin{array}{l}\text { Epidermal } \\
\text { melanocytes, } \\
\text { adnexae, nerve }\end{array}$ & $\begin{array}{l}\text { Distinction from } \\
\text { melanocytic hyperplasia } \\
\text { and LM confirmation } \\
\text { of melanocytic } \\
\text { differentiation }\end{array}$ \\
\hline D2-40 & $\begin{array}{l}\text { O-linked } \\
\text { sialoglycoprotein } \\
\text { on lymphatic endothelium }\end{array}$ & $\begin{array}{l}\text { D2-40 } \\
\text { (Signet/BioLegend) }\end{array}$ & $\mathrm{I}: 50$ & C & Adnexae & Evaluate for LVI \\
\hline $\mathrm{PHH} 3$ & $\begin{array}{l}\text { Regulation of chromatin } \\
\text { structure }\end{array}$ & $\begin{array}{l}\text { Histone H3 } \\
\text { (Ser I0) (Millipore) }\end{array}$ & $\mathrm{l}: 400$ & $\mathrm{~N}$ & $\begin{array}{l}\text { Mitotic figures in } \\
\text { epidermis, adnexa, } \\
\text { inflammatory cells }\end{array}$ & $\begin{array}{l}\text { Evaluate or confirm } \\
\text { mitotic figure }\end{array}$ \\
\hline $\mathrm{H} 3 \mathrm{KT}$ & $\begin{array}{l}\text { Regulation of chromatin } \\
\text { structure }\end{array}$ & $\begin{array}{l}\text { Histone H3 } \\
\text { (H3K79me3T80ph) } \\
\text { (Millipore) }\end{array}$ & $1: 400$ & $N$ & $\begin{array}{l}\text { Mitotic figures in } \\
\text { epidermis, adnexa, } \\
\text { inflammatory cells }\end{array}$ & $\begin{array}{l}\text { Evaluate or confirm } \\
\text { mitotic figure }\end{array}$ \\
\hline BRAFV600E & $\begin{array}{l}\text { Serine/threonine } \\
\text { protein kinase }\end{array}$ & $\begin{array}{l}\text { VEI } \\
\text { (Spring Bioscience) }\end{array}$ & $\mathrm{I}: 50$ & C & None available & $\begin{array}{l}\text { Detect the presence of } \\
\text { BRAFV600E mutation }\end{array}$ \\
\hline BAP-I & $\begin{array}{l}\text { Ubiquitin hydrolase } \\
\text { and enhance BRCA-I } \\
\text { tumor suppression }\end{array}$ & $\begin{array}{l}\text { C-4 } \\
\text { (Santa Cruz) }\end{array}$ & $\mathrm{I}: 150$ & $\mathrm{~N}$ & Keratinocytes & $\begin{array}{l}\text { Detect the presence of } \\
\text { BAP-I mutation }\end{array}$ \\
\hline
\end{tabular}

Abbreviations: C, cytoplasmic; IHC, immunohistochemistry; LM, lentigo maligna; LVI, lymphovascular invasion; N, nuclear.

can be seen in macrophages, fibroblasts, and mast cells and in a variety of spindle cell tumors in the differential diagnosis of melanoma (eg, dermal scar, dermatofibrosarcoma, leiomyosarcoma, neurofibroma, malignant peripheral nerve sheath tumor). ${ }^{37}$ In our experience, MiTF has clinical utility if incorporated with a panel of biomarkers in certain clinical scenarios: $:^{38}$ first, to enumerate melanocytes in the epidermis on chronic sun-damaged skin; second, to detect melanocytic differentiation in tumors negative for more conventional melanocytic markers (HMB45, anti-tyrosinase, and anti-Mart1); and third, to confirm melanocytic differentiation in rare isolated cells in vascular channels and the presence of lymphovascular invasion (LVI).

Since MiTF is expressed in the nucleus of melanocytes, it facilitates and accurately highlights the number of melanocytes seen in the epidermis (Figure 1A and B) and lesions of lentigo maligna (Figure 1C).$^{39}$ This is particularly useful in evaluating melanocytes on atrophic sun-damaged skin that typically harbors increased numbers of melanocytes in the epidermis, where perceived melanocytes numbers may be overestimated and their presence may be misinterpreted as lentigo maligna with Melan A since this marker labels the cytoplasm of

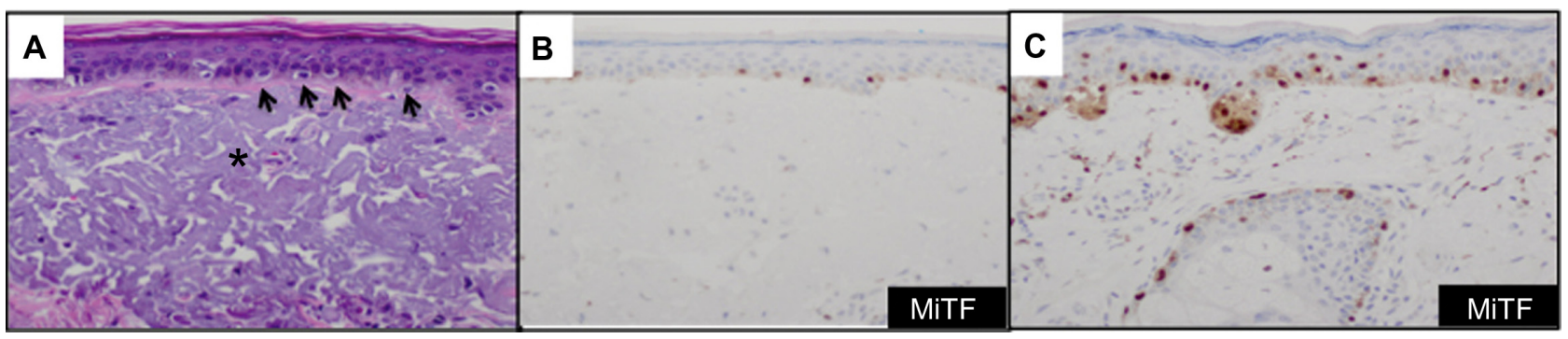

Figure I MiTF accurately enumerates the melanocytes in the epidermis of chronic sun exposed skin and in lesions of lentigo maligna.

Notes: (A) Chronic sun-damaged skin with atrophic epidermis and solar elastosis $\left({ }^{*}\right)$ with background increase in melanocytes along the dermal-epidermal junction (DEJ) (arrows) (H\&E stain, $\times 100$ ); (B) MiTF labels nuclei of melanocytes and allows for better enumeration of melanocytes along the DEJ (IHC stain, $\times$ I00); (C) Area of lentigo maligna with atypical melanocytes with back-to-back nuclei and pagetoid spread highlighted by MiTF (IHC stain, $\times 100)$.

Abbreviations: $\mathrm{H} \& \mathrm{E}$, hematoxylin and eosin; IHC, immunohistochemistry. 
melanocytes..$^{40}$ One factor contributing to the overestimation of melanocytes with Melan A is the cytoplasmic labeling of dendritic processes; also, Melan A has been shown to label occasional keratinocytes as "pseudomelanocytic nests." When we evaluate Melan A in this clinical setting, attention to labeling of only the cell bodies helps prevent overestimation of the number of melanocytes. A study by Nybakken et $\mathrm{al}^{39}$ demonstrated that the use of Melan A resulted in an estimated $23.3 \%$ higher melanocyte count in the epidermis compared with use of hematoxylin and eosin (H\&E)-stained sections in atypical intraepithelial melanocytic proliferations (lesions of concern for diagnosis of melanoma in situ); use of MiTF resulted in estimates of melanocytes similar to those observed with H\&E-stained sections. Thus, MiTF can be useful to distinguish pigmented actinic keratosis from melanoma in situ. ${ }^{42}$ In fact, compared with Melan A and HMB45, MiTF allowed greater distinction of melanocytes from keratinocytes with melanin pigment. ${ }^{43}$ The mean density of intraepithelial melanocytes in a $1.0 \mathrm{~mm}$ segment of epidermis was reported to be 27 positive MiTF cells in solar lentigines compared to 111.9 in melanoma in situ. ${ }^{43}$ Morphometric analysis identified greater than ten MiTF-positive nuclei per $200 \mu \mathrm{m}$ segment of H\&E-stained, section-favored melanoma in situ over solar lentigo. ${ }^{44}$ Although quantitative assessment is valuable, we also find it helpful to compare the background melanocytes with the central lesion in skin ellipse specimens. Typically, there should be crescendo-decrescendo density of melanocytes in the epidermis from the periphery-center of the lesion-periphery in examined cross-sections (either by H\&E or IHC) (Figure 2). Discrimination from background increase density of melanocytes in chronic sun damage skin from lentigo maligna may become more challenging in en face margin evaluation.

\section{Sox 10}

The Sox (Sry-related box) family of genes is involved in the development processes of testis, oligodendrocytes, the central nervous system, and chodrocytes. ${ }^{45}$ Sox 10 plays a pivotal role in neural crest cell development, and mutations in Sox 10 result in Waardenburg-Shah syndrome. Afflicted individuals exhibit pigmentary alterations and nervous system defects. ${ }^{46}$ Sox 10 directly regulates expression of MiTF and other genes essential in melanin synthesis..$^{47,48} \mathrm{~A}$ study by Bondurand et $\mathrm{al}^{49}$ showed that Sox10 in synergy with PAX3 bind directly to the MiTF promoter; thus, regulating MiTF expression. Consequently, Sox 10 has emerged as a useful tissue biomarker in melanocytic neoplasms. ${ }^{50,51}$ Similar to MiTF, Sox 10 protein is expressed in the nucleus, and the utility of Sox 10 in evaluation of melanocytic lesions parallels that of MiTF. In particular, like MiTF, Sox 10 facilitates the enumeration of melanocytes in the epidermis on chronic sun-damaged skin, and minimizes the overestimation of melanocytes. Sox 10 also facilitates the distinction of pigmented actinic keratosis and melanocytic hyperplasia from lentigo maligna. ${ }^{42}$

Sox10 is expressed in Schwann cells, myoepithelial cells, granular cells, adnexal structures, and salivary glands. Since the expression of Sox 10 has been limited to tumors of melanocytic, Schwannian, or myoepithelial differentiation, Sox10 has become useful in differential diagnosis of melanoma. The sensitivity of Sox10 in melanoma with various morphologies and patterns (eg, spindle, nodular, desmoplastic, metastatic) is comparable to that of S100 and is greater than $95 \% .^{50,52,53}$ Sox 10 and MiTF differ, however, in specificity. Sox 10 expression is absent in fibroblasts and macrophages and thus can aid in evaluating excision specimens for residual tumor. ${ }^{54}$ Sox 10

\section{Periphery}

Center

Periphery
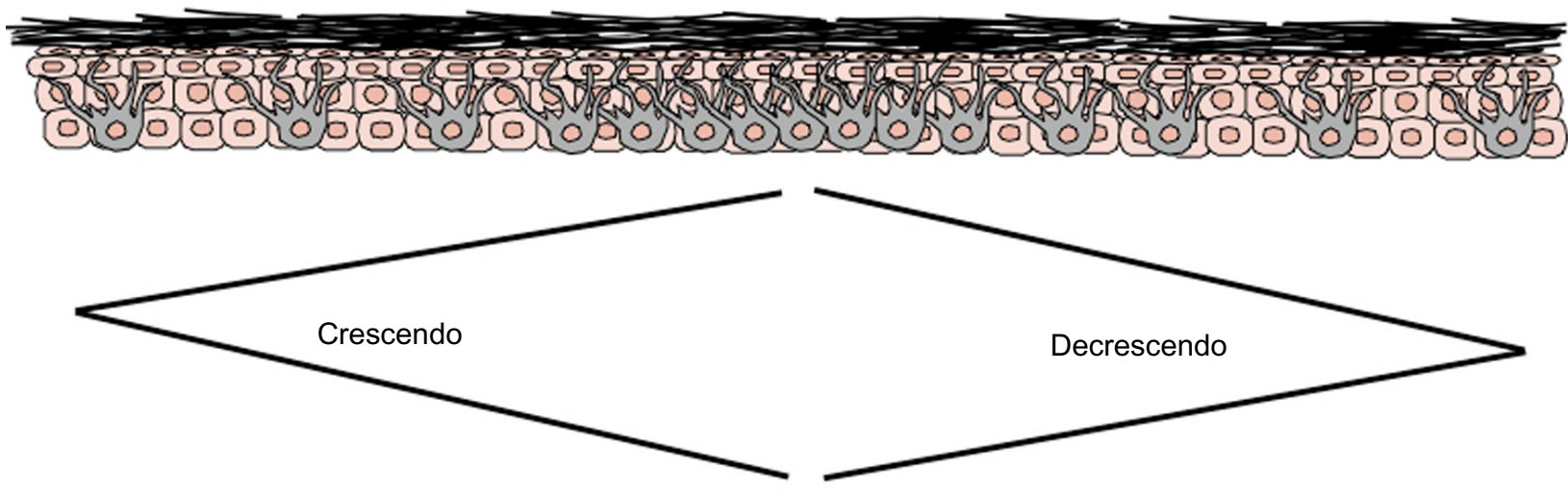

Figure 2 Evaluation of bread-loafed cross-sections of peripheral margins allows for comparison of the background increased density of melanocytes, reflective of chronic sun damage (at the periphery), with area of lentigo maligna (at the center). 


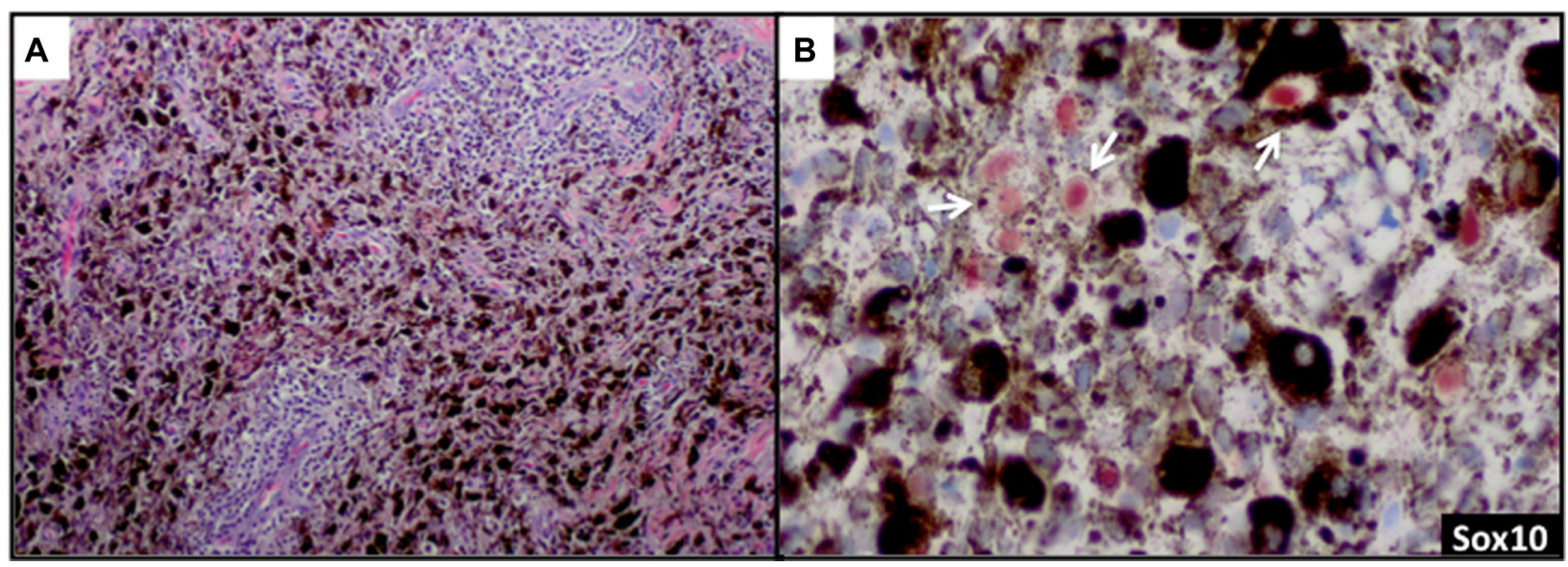

Figure 3 Sox 10 identifies rare tumor cells in heavily regressed areas of melanoma.

Notes: (A) Melanoma nodule with extensive regression with melanophages (H\&E stain, $\times 40$ ); (B) Sox 10 labels nucleus (arrows) of scattered viable melanoma cells in the regressed nodule with an absence of labeling in pigmented macrophages (IHC stain, $\times 400)$.

Abbreviations: $\mathrm{H} \& \mathrm{E}$, hematoxylin and eosin; IHC, immunohistochemistry.

has also been reported to be a reliable marker in evaluating sentinel lymph nodes for metastatic melanoma. ${ }^{55}$ In addition to these uses for Sox10, we have found this tissue biomarker to be helpful in identifying rare tumor cells in a heavily regressed area of metastatic melanoma with abundant melanophages (Figure 3A). The nuclear labeling of Sox 10 (preferably with red chromogen to contrast melanin pigment in the cytoplasm of the macrophages) confirms the presence of isolated melanoma cells (Figure 3B) but not macrophages, and thus may have important clinical implications in staging.

\section{Markers of vascular invasion D2-40}

The endothelial marker D2-40 (podoplanin) is a highly specific monoclonal antibody for lymphatic endothelium but does not react with blood vessel endothelium; thus, D2-40 is a selective marker to highlight LVI by tumor cells. ${ }^{56}$ Use of D2-40 in cutaneous melanoma, compared with use of HE stain alone, increased the frequency of both intratumoral and peritumoral LVI detection. ${ }^{57,58}$ In fact, detection of LVI with D2-40 in cutaneous melanoma correlated with positive sentinel lymph nodes and worse overall and disease-free survival (Figure 4A and B). ${ }^{58,59}$ The importance of LVI detection with D2-40 is not limited to cutaneous melanomas but offers prognostic value in other human cancers such as endometrial, breast, esophageal, colorectal, and Merkel cell cancers. ${ }^{60-63}$

CD34 and CD31 are panvascular markers that label both lymphatic and blood vessel endothelium. The sensitivity of CD34 and CD31 in identifying lymphatic endothelium is lower than that of D2-40. ${ }^{64,65}$ In addition, CD31 is reactive in macrophages. These qualities make CD34 and CD31 suboptimal markers in the detection of LVI in cutaneous melanoma.

\section{Dual IHC marker with MiTF/D2-40 or Sox I0/D2-40}

The use of double IHC stains to evaluate melanocytic lesions is generally available in academic settings and some private laboratories. ${ }^{66}$ At our institution, to confirm histologic suspicion of LVI in tumors that histologically harbor poor prognostic attribute(s) (eg, ulceration, mitotic figures, thick tumors) in patients with cutaneous melanomas, we routinely evaluate for LVI with D2-40 in lesions with adequate dermal component amenable to further IHC studies. Since a vascular collection of inflammatory cells (eg, lymphocytes or monocytes) highlighted by D2-40 may mimic melanoma LVI, we have developed a dual IHC protocol that allows us to identify lymphatic endothelium with D2-40 and confirm melanocytic differentiation in cells within the highlighted lymphatic vessel with either MiTF or Sox 10 (Figure 4C and D). Both dual IHC markers with MiTF/D2-40 or Sox10/D2-40 have clinical utility. An advantage of using Sox10 in some instances will be in lesions negative for MiTF (eg, spindle/ desmoplastic melanomas) or if there is concern for MiTF reactivity with macrophages.

\section{Markers of mitotic figures $\mathrm{PHH} 3$}

Modifications of histone tails are critical events in melanoma cells, and condensation of chromatin is an essential biologic 


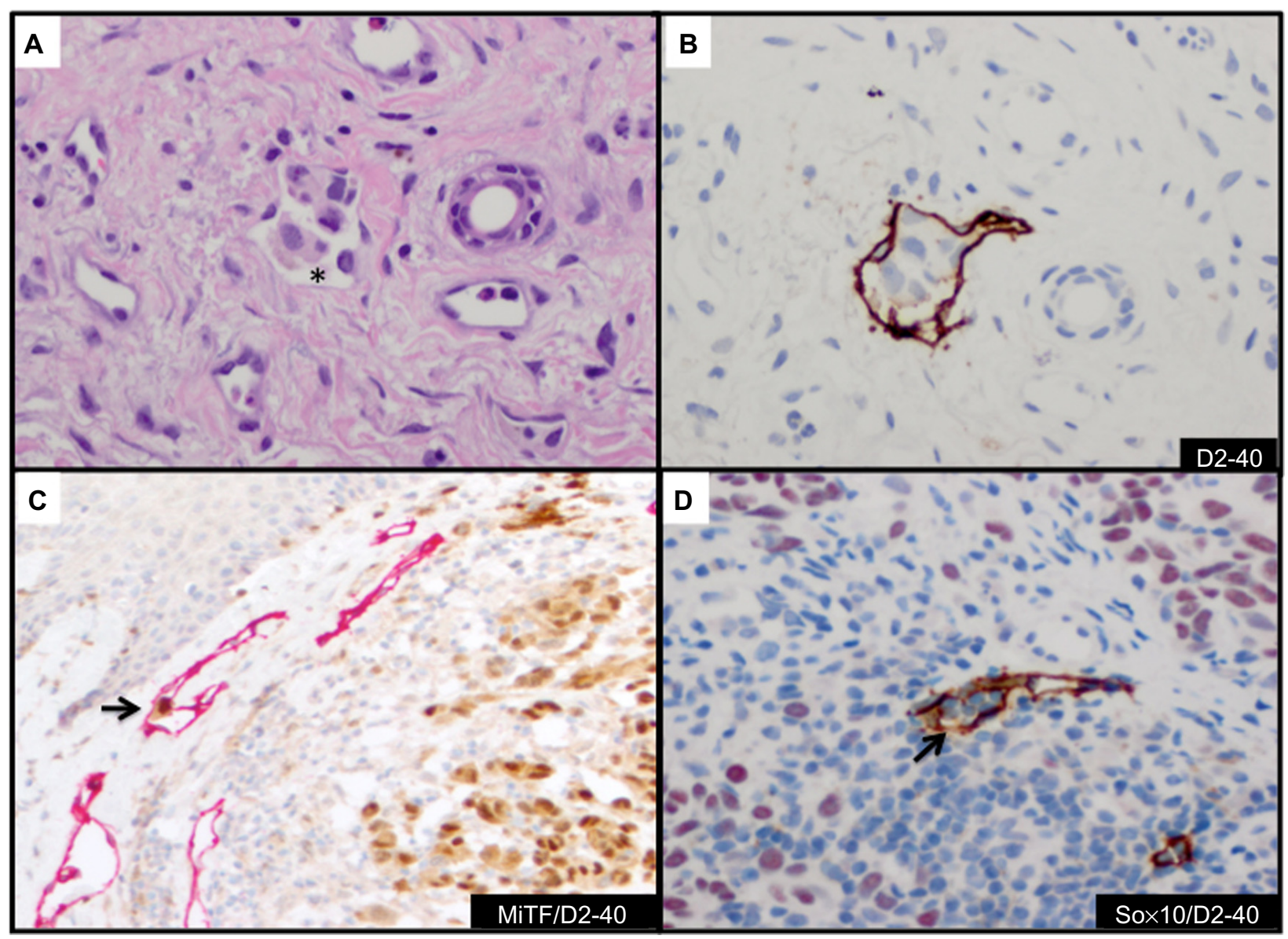

Figure 4 Detection and confirmation of lymphovascular invasion.

Notes: (A) Cluster of melanoma cells in a vascular-like space (*) (H\&E stain, $\times 400)$; (B) D2-40 highlights lymphatic vessel and confirms LVI (IHC stain, $\times 400)$; (C) Dual IHC stain with MiTF (brown, nuclear) and D2-40 (red, cytoplasmic) highlights isolated melanoma cell in lymphatic channel (arrow) ( $\times 400)$; (D) Dual IHC stain with SoxI0 (red, nuclear) and D2-40 (brown, cytoplasmic) confirms the collection of inflammatory cells (arrow) in a lymphatic vessel (arrow) and the absence of LVI ( $\times 400)$. Note the adjacent Sox I0-positive melanoma cells.

Abbreviations: H\&E, hematoxylin and eosin; IHC, immunohistochemistry; LVI, lymphovascular invasion.

process in preparation for cell division.${ }^{67}$ Detection of mitotic figures is an important histologic feature in both the diagnosis and prognosis of melanoma. The presence of mitotic figures in melanoma correlates with worse prognosis and defines a subset of thin melanomas (Breslow thickness $\leq 1.0 \mathrm{~mm}$ ) classified as T1b (American Joint Committee on Cancer [AJCC]). ${ }^{2} \mathrm{PHH} 3$ (phosphorylation of histone $\mathrm{H} 3$ at serine 10) has been shown to be associated with chromatin condensation at $\mathrm{G} 2$ and $\mathrm{M}$ phases of the cell cycle. ${ }^{68}$

Immunodetection of mitotic figures in cutaneous melanoma with PHH3 has been shown to facilitate the mitotic figure count, demonstrate increased risk of metastasis, and was correlated with worse survival. ${ }^{69-71} \mathrm{PHH} 3$ is a sensitive and specific mitotic-associated histone marker; it is reactive in all phases of the mitotic cycle and is absent in apoptotic cells. ${ }^{70}$ The clinical utility of PHH3 at our institution is to confirm/detect mitotic figures in melanocytic lesions on a case-by-case basis. Since the AJCC-TNM (tumor, nodes, metastasis) melanoma classification system was based on detection of mitotic figures from a data set where mitotic figures were reported on "routine" $H \& E$ sections, exhaustive examination of multiple levels to search only for mitotic figures is not warranted., 2,72,73 The application of PHH3 in search for mitotic figures for all melanomas is not currently part of the standard operating procedure at our institution. This further ensures that we do not exhaust the tissue block in search for mitotic figures in situations where further molecular studies may become necessary.

\section{Dual IHC marker with Mart I/PHH3}

A variety of proliferative cells in the skin may be reactive with PHH3, including lymphocytes and macrophages that may make detection of tumor mitotic figures a challenge. A dual IHC stain with Mart1/PHH3 allows identification of mitotic figures in melanoma cells (Figure 5B). Dual IHC staining with Mart1/PHH3, compared with $\mathrm{PHH} 3$ staining alone, improved specificity and time in the detection of 


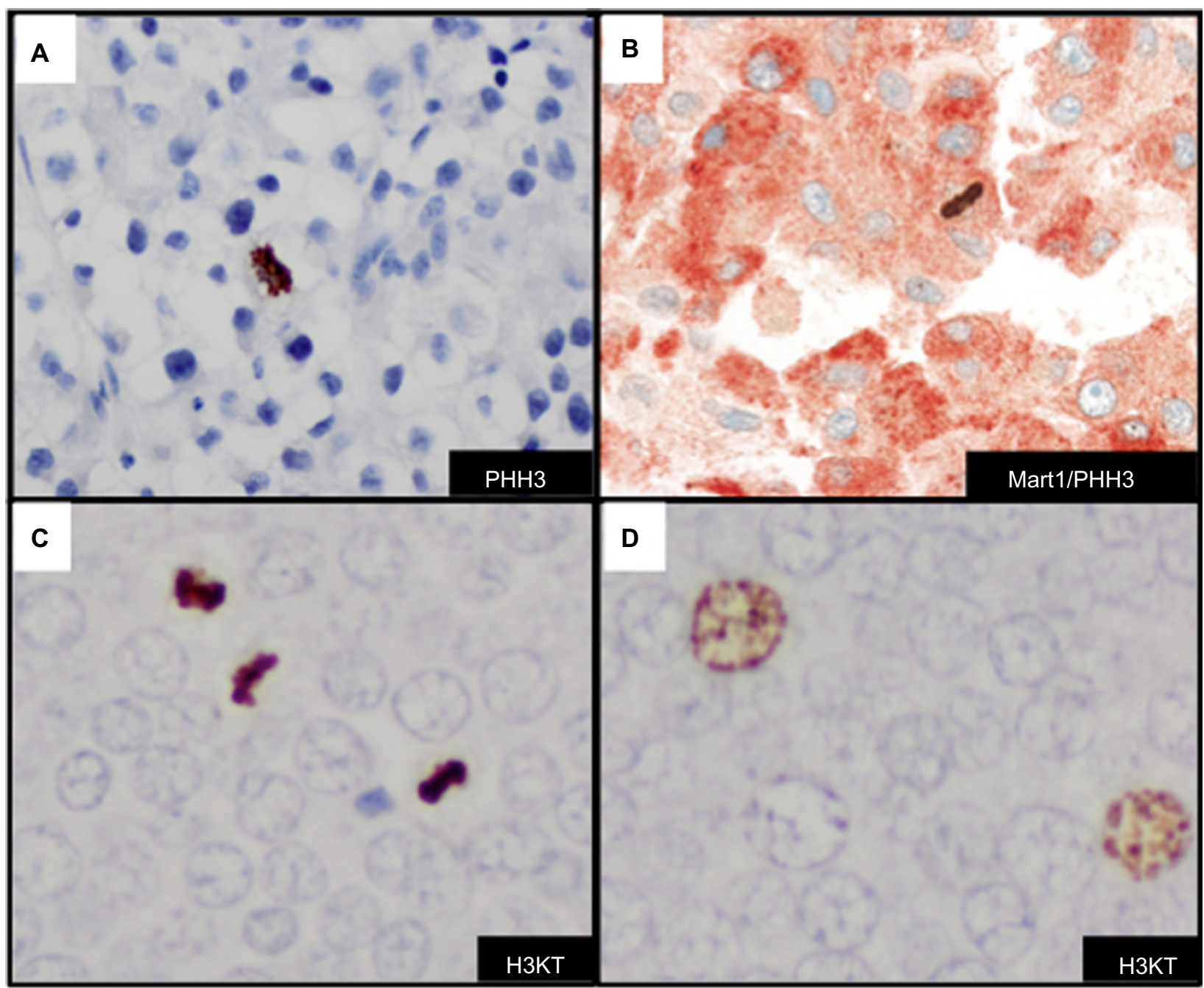

Figure 5 Detection of mitotic figures and $\mathrm{G} 2+$ tumor nuclei with histone markers.

Notes: (A and C) Detection of mitotic figure(s) with PHH3 and H3KT (anti-H3K79me3TH80ph) (IHC stain, $\times 400$ ); (B) Dual IHC stain with MartI (red, cytoplasmic) and $\mathrm{PHH} 3$ (brown, nuclear) confirms mitotic figure in melanoma cell $(\times 400)$; (C) Mitotic figure highlighted with H3KT in Merkel cell carcinoma (MCC) (IHC stain, $\times 400)$; (D) G2+ tumor nuclei detected by H3KT in MCC (IHC stain, $\times 400)$.

Abbreviation: IHC, immunohistochemistry.

mitotic figures in melanoma cells. ${ }^{70,74}$ Misinterpretation of PHH3-positive inflammatory cells can be avoided with antiMart1/PHH3, and this marker is typically used in our clinical practice to confirm mitotic figures in melanoma cells.

\section{Anti-H3K79me3T80ph}

Dynamic structural changes in chromatin are critical in the stage of the cell cycle. Chromatin condensation is important for proper cell division. A dual modified phosphohistone $\mathrm{H} 3$ marker anti-H3K79meT80ph (H3KT) is associated with mitotic figures in cutaneous melanoma. ${ }^{75} \mathrm{H} 3 \mathrm{KT}$ was found significantly in $\mathrm{G} 2 / \mathrm{M}$ phase of the cell cycle in asynchronous HeLA cells and essentially undetectable levels in G0/G1 and S phases of the cell cycle. ${ }^{75}$ More recently, studies indicate that H3KT may in fact recognize dual modified histone $\mathrm{H} 3 \mathrm{~K} 9$ me3S10ph
(H3KS). ${ }^{76}$ The detection of mitotic figures and G2+ tumor nuclei with H3KT identified a subset of cutaneous melanomas with a more aggressive clinical course. Furthermore, the combined mitotic figure count and G2+ tumor nuclei correlated with worse survival in a cohort of patients with Merkel cell carcinoma (Figure $5 \mathrm{C}$ ). ${ }^{77} \mathrm{H} 3 \mathrm{KT}$ or anti-H3KS is an emerging mitotic-associated histone marker that in a subset of tumors highlights the prognostic value of detection of G2+ tumor nuclei in human cancers (Figure 5D). Since H3KT identifies mitotic figures in any proliferating cell, the type of cell with mitosis may be further identified with incorporation of another IHC marker (eg, Mart-1/H3KT for proliferating melanocytes or CK20/H3KT for proliferating Merkel cells). Additional studies with H3KS and H3KT and double IHC marker studies are warranted for further clinical application. 


\section{Marker of mutation status Anti-BRAFV600E}

Analysis of the aberrant activation of the MAPK signaling pathway in a subset of melanomas with $B R A F$ mutations coupled with the development of selective RAF inhibitors that target mutated BRAF protein has revolutionized therapy for patients with advanced-stage disease. Approximately $50 \%-60 \%$ of cutaneous melanomas harbor $B R A F$ mutations that involve a thymine to adenine DNA base point mutation that replaces the amino acid valine with glutamic acid at the 600 position (BRAF V600E). ${ }^{7}$ A variety of molecular platforms exist for determining the presence of $B R A F V 600 E$ mutation in formalin-fixed paraffin-embedded (FFPE) tissue samples of melanoma, including pyrosequencing, the cobas BRAF V600 mutation test developed by Roche, and next-generation sequencing platforms. ${ }^{10}$ Molecular testing, however, often requires a specialized laboratory, may be technically demanding, and is associated with increased costs and time for completing the test. Alternatively, circulating plasma DNA with BRAF mutation reported by Denis et $\mathrm{a}^{78}$ may aid in predicting patients who may respond to BRAF inhibitor therapy.

Results from detecting BRAFV600E mutations in melanoma with use of molecular tests with IHC methods are highly correlated with results from IHC staining with anti-BRAFV600E (clone VE1), with a sensitivity of $97 \%-100 \%$ and a specificity of $98 \%-100 \%{ }^{79-81}$ IHC expression of mutant BRAFV600E is typically diffuse throughout the cytoplasm of melanoma cells (Figure 6A). At times, focal cytoplasmic labeling of melanoma cells occurs with BRAFV600E IHC (Figure 6B), which has also been shown to correlate with the presence of the BRAFV600E mutation. ${ }^{82}$ These findings suggest that IHC analysis with anti-BRAFV600E is important to identify a subset of tumors

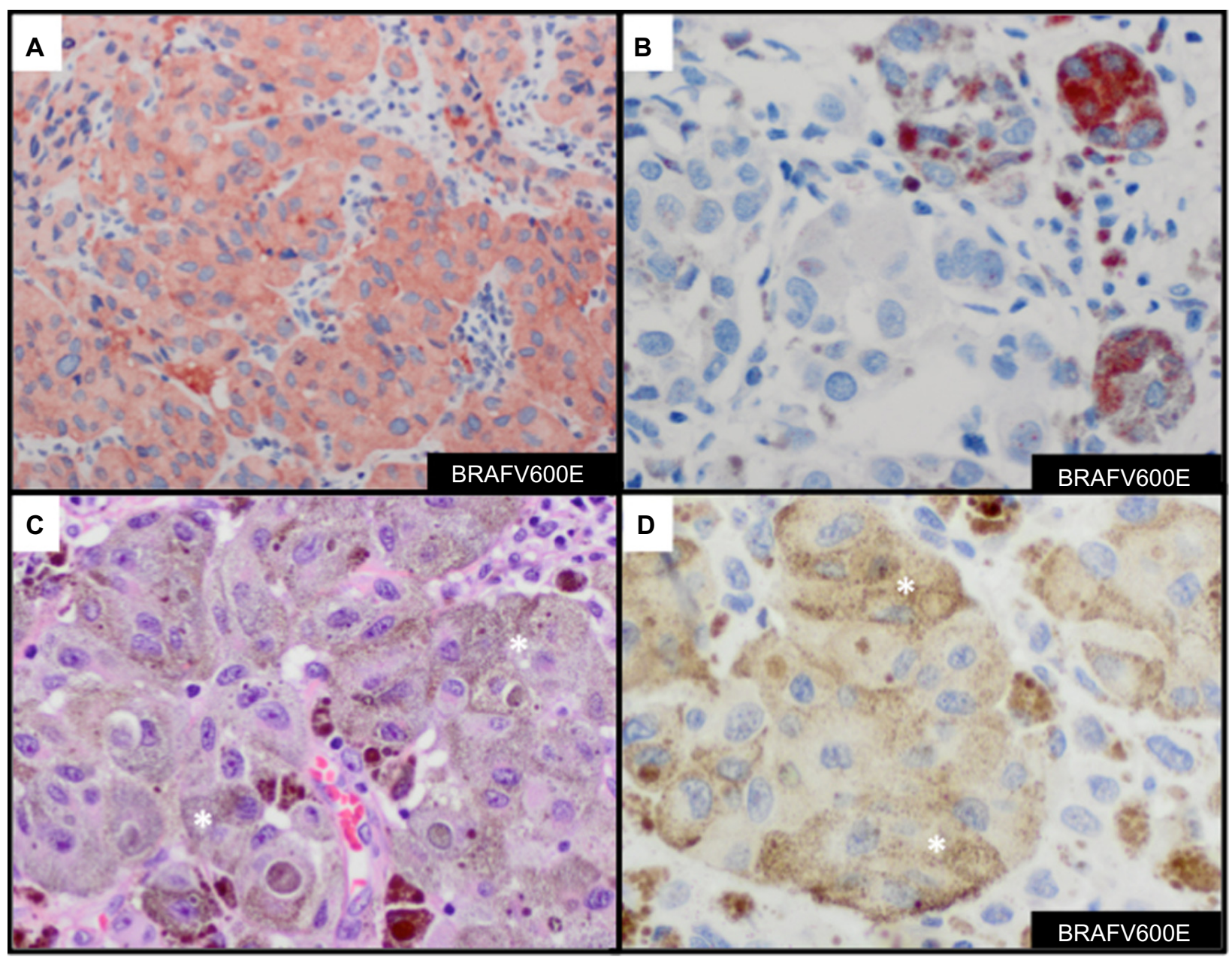

Figure 6 Immunohistochemcial evaluation of BRAFV600E mutation status in melanoma.

Notes: (A) Melanoma cells with diffuse, cytoplasmic labeling with anti-BRAFV600E (IHC stain, chromagen AEC, $\times 400$ ); (B) Focal labeling of melanoma cells with anti-BRAFV600E and the presence of tumor heterogeneity in a subset of tumors (IHC stain, chromagen AEC, $\times 400)$; (C) Melanoma cells with notable melanin pigment (H\&E stain, $\times 400)$; (D) Melanoma cells negative for anti-BRAFV600E; Brown color in cytoplasm of melanoma cells is melanin pigment $(*)$ and not DAB chromagen ( IHC stain, DAB, $\times 400$ ). Abbreviations: AEC, 3-amino-9-ethylcarbazole; DAB, diaminobenzidine; H\&E, hematoxylin and eosin; IHC, immunohistochemistry. 
that harbor BRAFV600E tumor heterogeneity. One should be aware of the chance of misinterpreting the presence of positive BRAFV600E stain in heavily pigmented tumor samples (Figure 6C), especially when the developing agent is a brown chromogen (eg, diaminobenzidine) (Figure 6D). An alternative would be to use a red chromogen (eg, 3-amino-9-ethylcarbazole or Texas red) as the developing agent, which may allow better discrimination of positive or negative staining. Reactivity of the developing agent in macrophages is another possible misinterpretation of BRAFV600E stain. Absence of the BRAFV600E mutation is seen as a negative stain. Nuclear labeling with the absence of cytoplasmic staining should be interpreted as negative. Our experience with BRAFV600E IHC stain (in preparation for publication) demonstrates high correlation with BRAFV600E mutation status and protein expression with anti-BRAFV600E antibody.
Anti-BAP- I

BAP-1 (BCRA1 associated protein-1) protein is an ubiquitin hydrolase that binds to BRCA1 and functions as a tumor suppressor. ${ }^{83}$ Germline mutations in $B A P-1$ have been described that predispose affected family members to uveal and cutaneous melanomas and development of melanocytic lesions with distinct clinical and histologic features ${ }^{84,85}$ Affected individuals present with multiple (range 5-50 lesions) well-circumscribed dome-shaped papules near the second decade of life. ${ }^{84,85}$ Histologically, the melanocytic lesions are located predominantly in the dermis and are composed of epithelioid melanocytes with abundant cytoplasm and distinct nucleoli. The lesions demonstrate similar cytologic features seen with Spitz nevi (Figure 7A). Similar lesions develop in the context of somatically acquired $B A P-1$ loss. IHC analysis with antiBAP-1 demonstrates loss of nuclear staining in melanocytic

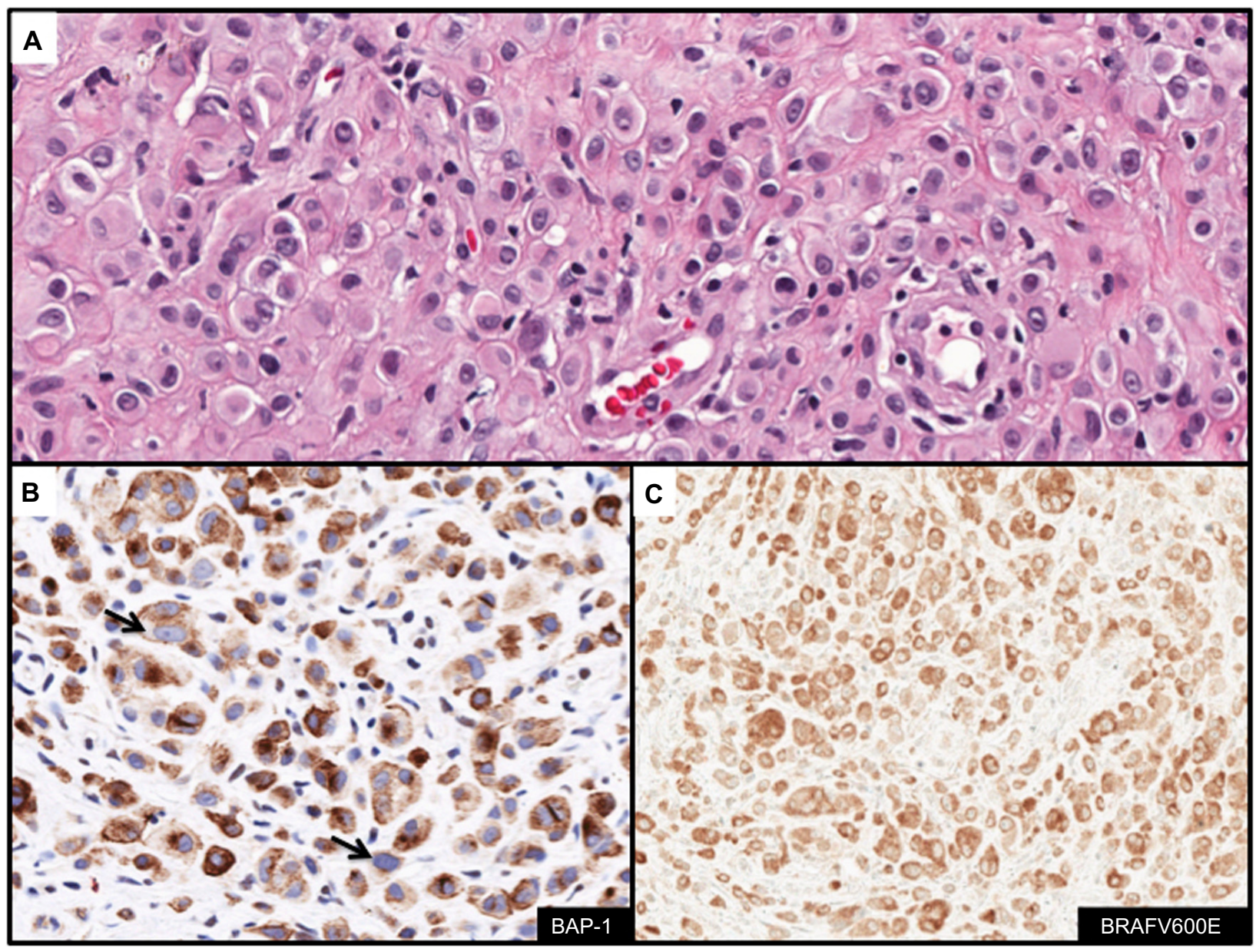

Figure 7 Immunohistochemcial evaluation of BAP-I and BRAFV600E status in melanocytic lesions.

Notes: (A) Melanocytic nevus composed of sheets of epithelioid-shaped melanocytes in the dermis (H\&E stain, $\times 400$ ); (B) Anti-BAP-I demonstrates loss of nuclear expression in melanocytes (arrows) indicative of the presence of BAP-I mutation (IHC stain, $\times 400$ ); (C) Diffuse cytoplasmic expression of anti-BRAFV600E (IHC stain, $\times 400$ ). Abbreviations: H\&E, hematoxylin and eosin; IHC, immunohistochemistry. 
lesions with $B A P-1$ mutations (Figure 7B). Furthermore, a significant proportion of BAP-1 lesions also frequently harbor a BRAFV600E mutation (Figure 7C). The combined features of BRAFV600E expression and loss of BAP-1 constitutes a distinct subset of Spitz nevi analogous to those harboring gains in chromosome $11 \mathrm{p}$ together with HRAS mutation. ${ }^{86}$

\section{Summary of emerging clinical utility of biomarkers in melanoma}

MiTF and Sox10 are both useful biomarkers in identification of melanocytic differentiation and to enumerate the melanocytes along the dermal-epidermal junction in setting of chronic sun-damaged skin. These markers may aid in margin control and in the diagnosis of melanoma. Sox 10 has further utility in the distinction between melanoma cells and macrophages in extensively regressed nodules of melanoma and in examination of lymph nodes since this marker exhibits greater melanocytic specificity. D2-40 exposes vascular invasion in a subset of melanomas, and use of double IHC marker MiTF/D2-40 or Sox10/D2-40 confirms the presence or absence of melanoma cells in the vascular lumen. PHH3 identifies mitotic figures and Mart-1/ PHH3 double IHC stain will confirm mitosis in cells with melanocytic differentiation. Detection and confirmation of mitotic figures in melanocytes may have clinical impact on $\mathrm{T}$ stage of thin melanomas (Breslow thickness $\leq 1.0 \mathrm{~mm}$ ). H3KT identified mitotic figures and G2+ tumor nuclei and may have prognostic implications in melanoma as well as Merkel cell carcinoma. Anti-BRAFV600E identifies melanomas that harbor BRAFV600E mutation and is a useful surrogate marker in the evaluation of BRAF mutation status in melanoma patients. Anti-BAP-1 allows for identification of melanocytic neoplasms with BAP-1 mutations and distinction from Spitz nevi and BAPomas when combined BRAFV600E and BAP-1 mutations coexist. Finally, next-generation sequencing and gene expression profiling may have some future diagnostic and prognostic utility in a subset of melanocytic lesions. ${ }^{87,88}$

\section{Conclusion}

Melanoma is a deadly skin disease that provides clinical challenges in diagnosis and treatment. However, the use of established and emerging tissue biomarkers will aid in the interpretation of difficult melanocytic lesions, provide prognostic information, identify mutation status, and allow the selection of patients who may benefit from targeted therapy.

\section{Acknowledgments}

This work was supported by the National Institutes of Health/National Cancer Institute under award number P30CA016672.

\section{Disclosure}

The authors report no conflicts of interest in this work.

\section{References}

1. Siegel R, Ma J, Zou Z, Jemal A. Cancer statistics, 2014. CA Cancer J Clin. 2014;64(1):9-29.

2. Balch CM, Gershenwald JE, Soong SJ, et al. Final version of 2009 AJCC melanoma staging and classification. J Clin Oncol. 2009;27(36): 6199-6206.

3. Kozarewa I, Rosa-Rosa JM, Wardell CP, et al. A modified method for whole exome resequencing from minimal amounts of starting DNA. PLoS One. 2012;7(3): 32617

4. Hodis E, Watson IR, Kryukov GV, et al. A landscape of driver mutations in melanoma. Cell. 2012;150(2):251-263.

5. Ibrahim N, Haluska FG. Molecular pathogenesis of cutaneous melanocytic neoplasms. Annu Rev Pathol. 2009;4:551-579.

6. Ko JM, Fisher DE. A new era: melanoma genetics and therapeutics. J Pathol. 2011;223(2):241-250.

7. Davies H, Bignell GR, Cox C, et al. Mutations of the BRAF gene in human cancer. Nature. 2002;417(6892):949-954.

8. Xia J, Jia P, Hutchinson KE, et al. A meta-analysis of somatic mutations from next generation sequencing of 241 melanomas: a road map for the study of genes with potential clinical relevance. Mol Cancer Ther. 2014;13(7):1918-1928.

9. Woodman SE, Lazar AJ, Aldape KD, Davies MA. New strategies in melanoma: molecular testing in advanced disease. Clin Cancer Res. 2012;18(5):1195-1200.

10. Curry JL, Torres-Cabala CA, Tetzlaff MT, Bowman C, Prieto VG. Molecular platforms utilized to detect BRAF V600E mutation in melanoma. Semin Cutan Med Surg. 2012;31(4):267-273.

11. Slominski A, Tobin DJ, Shibahara S, Wortsman J. Melanin pigmentation in mammalian skin and its hormonal regulation. Physiol Rev. 2004;84(4):1155-1228.

12. Slominski A, Zmijewski MA, Pawelek J. L-tyrosine and L-dihydroxyphenylalanine as hormone-like regulators of melanocyte functions. Pigment Cell Melanoma Res. 2012;25(1):14-27.

13. Slominski A, Wortsman J, Plonka PM, Schallreuter KU, Paus R, Tobin DJ. Hair follicle pigmentation. J Invest Dermatol. 2005;124(1): 13-21.

14. Slominski A, Wortsman J, Luger T, Paus R, Solomon S. Corticotropin releasing hormone and proopiomelanocortin involvement in the cutaneous response to stress. Physiol Rev. 2000;80(3):979-1020.

15. Slominski AT, Zmijewski MA, Zbytek B, Tobin DJ, Theoharides TC, Rivier J. Key role of CRF in the skin stress response system. Endocr Rev. 2013;34(6):827-884

16. Chapman PB, Hauschild A, Robert C, et al; BRIM-3 Study Group. Improved survival with vemurafenib in melanoma with BRAF V600E mutation. N Engl J Med. 2011;364(26):2507-2516.

17. Kee D, McArthur G. Targeted therapies for cutaneous melanoma. Hematol Oncol Clin North Am. 2014;28(3):491-505.

18. Miller DM, Flaherty KT, Tsao H. Current status and future directions of molecularly targeted therapies and immunotherapies for melanoma. Semin Cutan Med Surg. 2014;33(2):60-67.

19. Kwong LN, Davies MA. Targeted therapy for melanoma: rational combinatorial approaches. Oncogene. 2014;33(1):1-9.

20. Solit DB, Rosen N. Resistance to BRAF inhibition in melanomas. N Engl J Med. 2011;364(8):772-774.

21. Bucheit AD, Davies MA. Emerging insights into resistance to BRAF inhibitors in melanoma. Biochem Pharmacol. 2014;87(3):381-389. 
22. Hodi FS, O'Day SJ, McDermott DF, et al. Improved survival with ipilimumab in patients with metastatic melanoma. $N$ Engl J Med. 2010;363(8):711-723.

23. Cooper ZA, Juneja VR, Sage PT, et al. Response to BRAF inhibition in melanoma is enhanced when combined with immune checkpoint blockade. Cancer Immunol Res. 2014;2(7):643-654.

24. Chi M, Ye Y, Zhang XD, Chen J. Insulin induces drug resistance in melanoma through activation of the PI3K/Akt pathway. Drug Des Devel Ther. 2014;8:255-262.

25. Chen J, Shao R, Zhang XD, Chen C. Applications of nanotechnology for melanoma treatment, diagnosis, and theranostics. Int J Nanomedicine. 2013;8:2677-2688.

26. Koss LG, Melamed MR, editors. Koss' Diagnostic Cytology and Its Histopathologic Bases. Vol 1. 5th ed. Philadelphia, PA: Lippincott Williams \& Wilkins; 2006.

27. Tetzlaff MT, Wang WL, Milless TL, et al. Ambiguous melanocytic tumors in a tertiary referral center: the contribution of fluorescence in situ hybridization (FISH) to conventional histopathologic and immunophenotypic analyses. Am J Surg Pathol. 2013;37(12):1783-1796.

28. Hemesath TJ, Steingrímsson E, McGill G, et al. microphthalmia, a critical factor in melanocyte development, defines a discrete transcription factor family. Genes Dev. 1994;8(22):2770-2780.

29. Fuse N, Yasumoto K, Suzuki H, Takahashi K, Shibahara S. Identification of a melanocyte-type promoter of the microphthalmiaassociated transcription factor gene. Biochem Biophys Res Commun. 1996;219(3):702-707.

30. Bentley NJ, Eisen T, Goding CR. Melanocyte-specific expression of the human tyrosinase promoter: activation by the microphthalmia gene product and role of the initiator. Mol Cell Biol. 1994;14(12): 7996-8006.

31. Yasumoto K, Yokoyama K, Shibata K, Tomita Y, Shibahara S. Microphthalmia-associated transcription factor as a regulator for melanocyte-specific transcription of the human tyrosinase gene. Mol Cell Biol. 1994;14(12):8058-8070.

32. Granter SR, Weilbaecher KN, Quigley C, Fletcher CD, Fisher DE Microphthalmia transcription factor: not a sensitive or specific marker for the diagnosis of desmoplastic melanoma and spindle cell (non-desmoplastic) melanoma. Am J Dermatopathol. 2001;23(3): 185-189.

33. Miettinen M, Fernandez M, Franssila K, Gatalica Z, Lasota J, SarlomoRikala M. Microphthalmia transcription factor in the immunohistochemical diagnosis of metastatic melanoma: comparison with four other melanoma markers. Am J Surg Pathol. 2001;25(2):205-211.

34. Ordóñez NG. Value of melanocytic-associated immunohistochemical markers in the diagnosis of malignant melanoma: a review and update. Hum Pathol. 2014;45(2):191-205.

35. Wick MR, Swanson PE, Rocamora A. Recognition of malignant melanoma by monoclonal antibody HMB-45. An immunohistochemical study of 200 paraffin-embedded cutaneous tumors. J Cutan Pathol. 1988;15(4):201-207.

36. Ohsie SJ, Sarantopoulos GP, Cochran AJ, Binder SW. Immunohistochemical characteristics of melanoma. J Cutan Pathol. 2008;35(5):433-444.

37. Busam KJ, Iversen K, Coplan KC, Jungbluth AA. Analysis of microphthalmia transcription factor expression in normal tissues and tumors, and comparison of its expression with S-100 protein, gp100, and tyrosinase in desmoplastic malignant melanoma. Am J Surg Pathol. 2001;25(2):197-204.

38. Ivan D, Prieto VG. Use of immunohistochemistry in the diagnosis of melanocytic lesions: applications and pitfalls. Future Oncol. 2010;6(7): 1163-1175.

39. Nybakken GE, Sargen M, Abraham R, Zhang PJ, Ming M, Xu X. MITF accurately highlights epidermal melanocytes in atypical intraepidermal melanocytic proliferations. Am J Dermatopathol. 2013;35(1): 25-29.

40. Prieto VG, Shea CR. Immunohistochemistry of melanocytic proliferations. Arch Pathol Lab Med. 2011;135(7):853-859.
41. Beltraminelli H, Shabrawi-Caelen LE, Kerl H, Cerroni L. Melan-a-positive "pseudomelanocytic nests": a pitfall in the histopathologic and immunohistochemical diagnosis of pigmented lesions on sun-damaged skin. Am J Dermatopathol. 2009;31(3):305-308.

42. Buonaccorsi JN, Prieto VG, Torres-Cabala C, Suster S, Plaza JA. Diagnostic utility and comparative immunohistochemical analysis of MITF-1 and SOX10 to distinguish melanoma in situ and actinic keratosis: a clinicopathological and immunohistochemical study of 70 cases. Am J Dermatopathol. 2014;36(2):124-130.

43. Kim J, Taube JM, McCalmont TH, Glusac EJ. Quantitative comparison of MiTF, Melan-A, HMB-45 and Mel-5 in solar lentigines and melanoma in situ. J Cutan Pathol. 2011;38(10):775-779.

44. Black WH, Thareja SK, Blake BP, Chen R, Cherpelis BS, Glass LF. Distinction of melanoma in situ from solar lentigo on sun-damaged skin using morphometrics and MITF immunohistochemistry. Am J Dermatopathol. 2011;33(6):573-578.

45. Kiefer JC. Back to basics: Sox genes. Dev Dyn. 2007;236(8): 2356-2366

46. Pingault V, Bondurand N, Kuhlbrodt K, et al. SOX10 mutations in patients with Waardenburg-Hirschsprung disease. Nat Genet. 1998;18(2):171-173.

47. Lee M, Goodall J, Verastegui C, Ballotti R, Goding CR. Direct regulation of the Microphthalmia promoter by Sox 10 links Waardenburg-Shah syndrome (WS4)-associated hypopigmentation and deafness to WS2. J Biol Chem. 2000;275(48):37978-37983.

48. Ludwig A, Rehberg S, Wegner M. Melanocyte-specific expression of dopachrome tautomerase is dependent on synergistic gene activation by the Sox 10 and Mitf transcription factors. FEBS Lett. 2004;556(1-3): 236-244.

49. Bondurand N, Pingault V, Goerich DE, et al. Interaction among SOX10, PAX3 and MITF, three genes altered in Waardenburg syndrome. Hum Mol Genet. 2000;9(13):1907-1917.

50. Nonaka D, Chiriboga L, Rubin BP. Sox10: a pan-schwannian and melanocytic marker. Am J Surg Pathol. 2008;32(9): 1291-1298.

51. Ordóñez NG. Value of SOX10 immunostaining in tumor diagnosis. $A d v$ Anat Pathol. 2013;20(4):275-283.

52. Agnarsdóttir M, Sooman L, Bolander A, et al. SOX10 expression in superficial spreading and nodular malignant melanomas. Melanoma Res. 2010;20(6):468-478.

53. Karamchandani JR, Nielsen TO, van de Rijn M, West RB. Sox10 and $\mathrm{S} 100$ in the diagnosis of soft-tissue neoplasms. Appl Immunohistochem Mol Morphol. 2012;20(5):445-450.

54. Ramos-Herberth FI, Karamchandani J, Kim J, Dadras SS. SOX10 immunostaining distinguishes desmoplastic melanoma from excision scar. J Cutan Pathol. 2010;37(9):944-952.

55. Blochin E, Nonaka D. Diagnostic value of Sox10 immunohistochemical staining for the detection of metastatic melanoma in sentinel lymph nodes. Histopathology. 2009;55(5):626-628.

56. Kahn HJ, Bailey D, Marks A. Monoclonal antibody D2-40, a new marker of lymphatic endothelium, reacts with Kaposi's sarcoma and a subset of angiosarcomas. Mod Pathol. 2002;15(4):434-440.

57. Niakosari F, Kahn HJ, Marks A, From L. Detection of lymphatic invasion in primary melanoma with monoclonal antibody D2-40: a new selective immunohistochemical marker of lymphatic endothelium. Arch Dermatol. 2005;141(4):440-444.

58. Petersson F, Diwan AH, Ivan D, et al. Immunohistochemical detection of lymphovascular invasion with D2-40 in melanoma correlates with sentinel lymph node status, metastasis and survival. J Cutan Pathol. 2009;36(11):1157-1163.

59. Doeden K, Ma Z, Narasimhan B, Swetter SM, Detmar M, Dadras SS. Lymphatic invasion in cutaneous melanoma is associated with sentinel lymph node metastasis. J Cutan Pathol. 2009; 36(7):772-780.

60. Weber SK, Sauerwald A, Pölcher M, et al. Detection of lymphovascular invasion by D2-40 (podoplanin) immunoexpression in endometrial cancer. Int J Gynecol Cancer. 2012;22(8):1442-1448. 
61. Lupinacci RM, Mello ES, Pinheiro RS, et al. Intrahepatic lymphatic invasion but not vascular invasion is a major prognostic factor after resection of colorectal cancer liver metastases. World J Surg. 2014;38(8):2089-2096.

62. Imamura Y, Watanabe M, Nagai Y, et al. Lymphatic vessel invasion detected by the D2-40 monoclonal antibody is an independent prognostic factor in node-negative esophageal squamous cell carcinoma. J Surg Oncol. 2012;105(3):277-283.

63. Lee JA, Bae JW, Woo SU, Kim H, Kim CH. D2-40, Podoplanin, and CD31 as a prognostic predictor in invasive ductal carcinomas of the breast. J Breast Cancer. 2011;14(2):104-111.

64. Kahn HJ, Marks A. A new monoclonal antibody, D2-40, for detection of lymphatic invasion in primary tumors. Lab Invest. 2002;82(9): 1255-1257.

65. Rose AE, Christos PJ, Lackaye D, et al. Clinical relevance of detection of lymphovascular invasion in primary melanoma using endothelial markers D2-40 and CD34. Am J Surg Pathol. 2011;35(10): 1441-1449.

66. Nielsen PS, Riber-Hansen R, Steiniche T. Immunohistochemical double stains against Ki67/MART1 and HMB45/MITF: promising diagnostic tools in melanocytic lesions. Am J Dermatopathol. 2011;33(4): 361-370.

67. Richards HW, Medrano EE. Epigenetic marks in melanoma. Pigment Cell Melanoma Res. 2009;22(1):14-29.

68. Juan G, Traganos F, James WM, et al. Histone H3 phosphorylation and expression of cyclins A and B1 measured in individual cells during their progression through G2 and mitosis. Cytometry. 1998;32(2): 71-77.

69. Schimming TT, Grabellus F, Roner M, et al. pHH3 immunostaining improves interobserver agreement of mitotic index in thin melanomas. Am J Dermatopathol. 2012;34(3):266-269.

70. Tetzlaff MT, Curry JL, Ivan D, et al. Immunodetection of phosphohistone $\mathrm{H} 3$ as a surrogate of mitotic figure count and clinical outcome in cutaneous melanoma. Mod Pathol. 2013;26(9):1153-1160.

71. Ladstein RG, Bachmann IM, Straume O, Akslen LA. Prognostic importance of the mitotic marker phosphohistone $\mathrm{H} 3$ in cutaneous nodular melanoma. J Invest Dermatol. 2012;132(4):1247-1252.

72. Gershenwald JE, Soong SJ, Balch CM; American Joint Committee on Cancer (AJCC) Melanoma Staging Committee. 2010 TNM staging system for cutaneous melanoma ... and beyond. Ann Surg Oncol. 2010;17(6):1475-1477.

73. Thompson JF, Soong SJ, Balch CM, et al. Prognostic significance of mitotic rate in localized primary cutaneous melanoma: an analysis of patients in the multi-institutional American Joint Committee on Cancer melanoma staging database. J Clin Oncol. 2011;29(16):2199-2205.

74. Ikenberg K, Pfaltz M, Rakozy C, Kempf W. Immunohistochemical dual staining as an adjunct in assessment of mitotic activity in melanoma. J Cutan Pathol. 2012;39(3):324-330.
75. Martinez DR, Richards HW, Lin Q, et al. H3K79me3T80ph is a novel histone dual modification and a mitotic indicator in melanoma. J Skin Cancer. 2012;2012:823534

76. Hammond SL, Byrum SD, Namjoshi S, et al. Mitotic phosphorylation of histone H3 threonine 80. Cell Cycle. 2014;13(3):440-452.

77. Henderson SA, Tetzlaff MT, Pattanaprichakul P, et al. Detection of mitotic figures and G2+ tumor nuclei with histone markers correlates with worse overall survival in patients with Merkel cell carcinoma. J Cutan Pathol. Epub September 26, 2014.

78. Denis MG, Khammari A, Vallee A, et al. Detection of BRAF mutations in the plasma of melanoma patients as an early marker of treatment efficiency. J Clin Oncol. 2014;32(5s)(Suppl; abstr 9069).

79. Capper D, Berghoff AS, von Deimling A, Preusser M. Clinical neuropathology practice news 2-2012: BRAF V600E testing. Clin Neuropathol. 2012;31(2):64-66.

80. Long GV, Wilmott JS, Capper D, et al. Immunohistochemistry is highly sensitive and specific for the detection of V600E BRAF mutation in melanoma. Am J Surg Pathol. 2013;37(1):61-65.

81. Colomba E, Hélias-Rodzewicz Z, Von Deimling A, et al. Detection of BRAF p.V600E mutations in melanomas: comparison of four methods argues for sequential use of immunohistochemistry and pyrosequencing. J Mol Diagn. 2013;15(1):94-100.

82. Busam KJ, Hedvat C, Pulitzer M, von Deimling A, Jungbluth AA. Immunohistochemical analysis of BRAF(V600E) expression of primary and metastatic melanoma and comparison with mutation status and melanocyte differentiation antigens of metastatic lesions. Am J Surg Pathol. 2013;37(3):413-420.

83. Jensen DE, Rauscher FJ. BAP1, a candidate tumor suppressor protein that interacts with BRCA1. Ann NY Acad Sci. 1999;886:191-194.

84. Aoude LG, Wadt K, Bojesen A, et al. A BAP1 mutation in a Danish family predisposes to uveal melanoma and other cancers. PLoS One. 2013;8(8):e72144.

85. WiesnerT, ObenaufAC, Murali R, et al. Germline mutations in BAP1 predispose to melanocytic tumors. Nat Genet. 2011;43(10):1018-1021.

86. Wiesner T, Murali R, Fried I, et al. A distinct subset of atypical Spitz tumors is characterized by BRAF mutation and loss of BAP1 expression. Am J Surg Pathol. 2012;36(6):818-830.

87. Clarke LE, Bess E, Moyers K, Kolquist KA, Rock C. The influence of a gene expression signature on the diagnosis and recommended treatment of melanocytic tumors by dermatopathologists. J Clin Oncol. 2014;32(5s)(Suppl; abstr TPS9111).

88. Siroy AE, Boland GM, Milton DR, et al. Beyond BRAF: clinical mutation panel testing by next-generation sequencing in advanced melanoma. J Invest Dermatol. Epub August 22, 2014.
Clinical, Cosmetic and Investigational Dermatology

\section{Publish your work in this journal}

Clinical, Cosmetic and Investigational Dermatology is an international, peer-reviewed, open access, online journal that focuses on the latest clinical and experimental research in all aspects of skin disease and cosmetic interventions. All areas of dermatology will be covered; contributions will be welcomed from all clinicians and
Dovepress

basic science researchers globally. This journal is indexed on CAS The manuscript management system is completely online and includes a very quick and fair peer-review system, which is all easy to use. Visit http://www.dovepress.com/testimonials.php to read real quotes from published authors. 